\title{
Pharmaco-economic Evaluation of Antibiotic Therapy Strategies in DRG-Based Healthcare Systems - A NeW Approach
}

\author{
M. H. Wilke, R. Grube \\ Dr. Wilke GmbH, Munich, Germany
}

\begin{abstract}
The cost of treatments especially in conditions where multiresistant bacteria are involved are a major issue in times where in most developed countries in the world payment systems based on diagnoses-related-groups (DRG) are in place. There is great evidence that especially the length of stay in hospital (LOS), the time in the intensive care unit (ICU-days) and the hours of mechanical ventilation (HMV) are major cost drivers.

While established methods of pharmacoeconomical analyses focus on the efficiency of drugs from healthcare system perspective, these data are often not sufficient for improving treatment strategies in a given hospital context.

We developed a system that allows the analysis of patients with severe infections on the basis of routine data that is also used for reimbursement. These data contain a lot of information concerning the clinical conditions. By using the ICD-coding we developed an algorithm which allows the detection of patients with infections and gives information on the potential financial outcome of these patients. By using the analysis it is possible to identify subsets of infections and the patient records that had a potentially negative DRG-result, i.e. the costs are higher than the reimbursement. When identified the patient records undergo a peer review, where the clinical situation and the antibiotic therapy are reviewed by medical experts. In case simulations it is possible to find out if a different therapeutic approach, e.g. by different choices in initial (empirical) antibiotic treatment would have caused other outcomes.
\end{abstract}

Data driven analyses together with peer reviews of patient records are a useful tool to examine antibiotic treatment strategies and to establish changes that again can be reviewed on a regular basis. Doing this a continous improvement process can be established in hospitals which can lead to a better balance of clinical and economical outcomes in patients with severe infections. Moreover these analyses are helpful in assessing the literature on economical benefits of new therapies.

\section{Abbreviations:}

ALOS $=$ Average length of stay in a given DRG, basis for determining whether a patient causes more costs than reimbursement;

$\mathrm{CAP}=$ community acquired pneumonia;

$\mathrm{CC}=$ complications and comorbidities, conditions (like secondary diagnoses) that cause higher resource consumption;
DRG = diagnoses related groups, systems to classify patients based on their resource consumptions;

HAP = hospital acquired pneumonia;

$\mathrm{HMV}=$ hours of mechanical ventilation;

ICU-days = treatment days on an intensive care unit;

LOS = length of stay in hospital;

MDS = medical services of the statuary health insurance in Germany;

QALY = quality adjusted life years;

$\mathrm{W}=$ with;

$\mathrm{W} / \mathrm{O}=$ without

\section{INTRODUCTION}

Antibiotic therapy directed against multiresistent bacteria is a significant cost driver in clinical medicine. Due to various reasons, the costs of new antibiotics are comparatively high and some multiresistant bacteria can or should only be treated with new antibiotics. Moreover, most complicated bacterial infections requiring long treatment durations occur in the hospital setting, often in intensive care units. It is a well established notion that prolonged length of stay in the hospital (LOS), the time spent in intensive care units (ICU days) and the hours of mechanical ventilation (HMV) are the main cost drivers in this setting [1-6].

The evaluation of the economical effectiveness of pharmacological therapies is gaining more and more importance. While most of these pharmacoeconomical analyses are intended to show effectiveness of a new drug versus the current standard-of-care from a healthcare system perspective (cost-effectiveness studies, prospective modelling, using quality-adjusted-lifeyears (QUALYs) and other parameters), these studies do not necessarily answer the budget-related questions of clinicians or even the administrators in a hospital [7-10].

Finally, in most developed countries so-called diagnosis-related groups (DRG) are used for hospital budgeting, reimbursement or resource allocation. DRGs are payment groups that determine the reimbursement for a certain type of patient group that was found to be economically homogenous. For example, the Germany system provides DRG-directed payment for respiratory tract infections with or without „,complications or comorbidities (CC)". The following table gives an overview of DRGs for respiratory tract infections, their cost-weights, their payment (assuming a base price for cost weight 1.0 of $€ 2,900$.-) and the related length of stay (LOS) in hospital, see Table 1. 
Table 1. Overview of DRG E77 - respiratory tract infections.

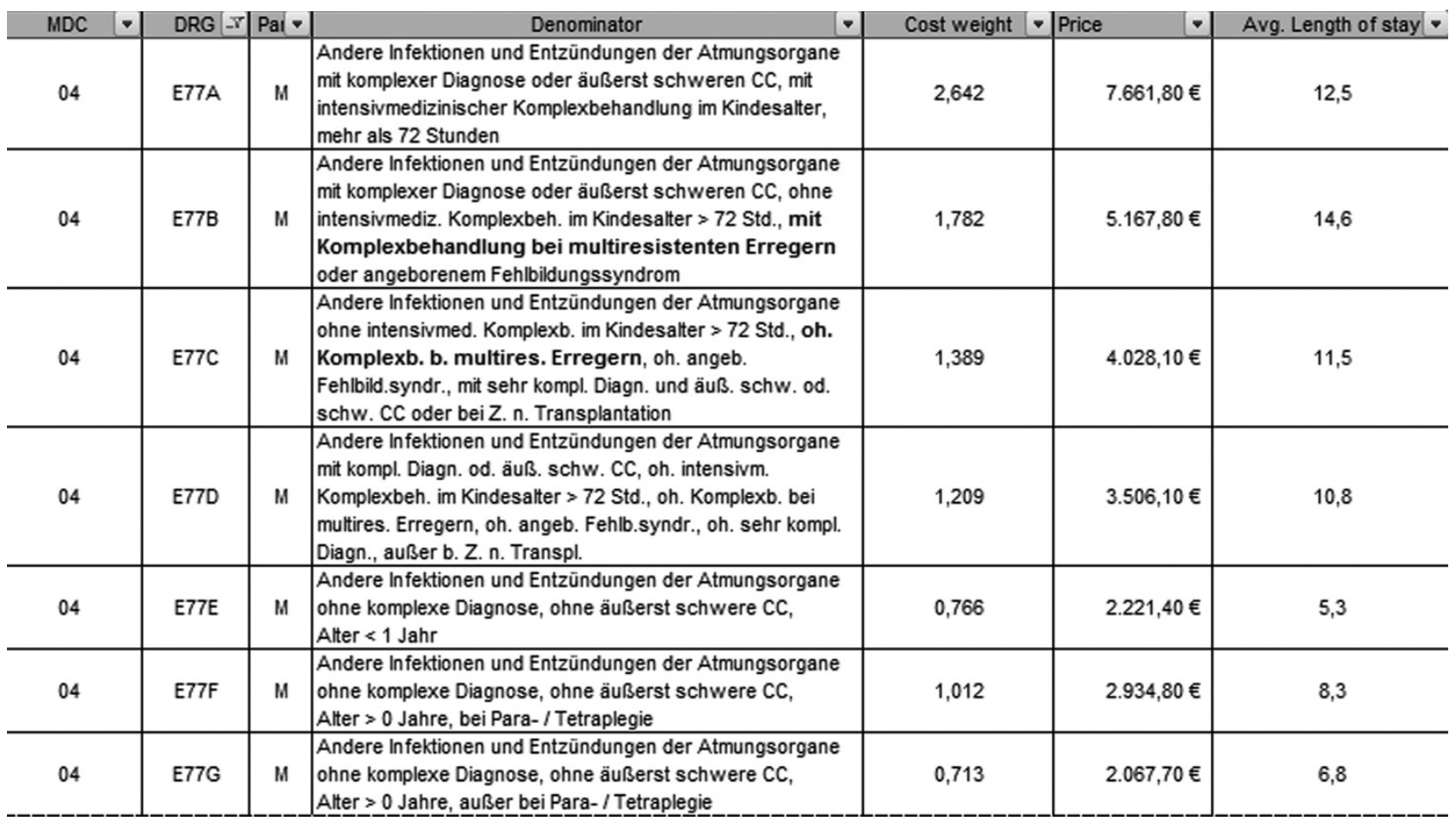

Table 2. Cost matrix for DRG E77B.

\begin{tabular}{|c|c|c|c|c|c|c|c|c|c|c|c|}
\hline \multirow[b]{3}{*}{ Kostenbereich } & \multicolumn{3}{|c|}{ Personalkosten: } & \multicolumn{5}{|c|}{ Sachkosten: } & \multicolumn{2}{|c|}{ Pers.- u. Sachkosten: } & \multirow[b]{3}{*}{ Summe } \\
\hline & \multirow{2}{*}{$\begin{array}{c}\text { Ärzticher } \\
\text { Dienst }\end{array}$} & \multirow{2}{*}{\begin{tabular}{c|} 
Plegedienst \\
2 \\
\end{tabular}} & \multirow{2}{*}{\begin{tabular}{c|}
$\begin{array}{c}\text { med.flechn. } \\
\text { Dienst }\end{array}$ \\
3 \\
\end{tabular}} & \multicolumn{2}{|c|}{ Arzneimitel } & \multirow{2}{*}{\begin{tabular}{|c|} 
Implantate / \\
Transplant. \\
5
\end{tabular}} & \multicolumn{2}{|c|}{ Übriger med. Bedarf } & \multirow{2}{*}{\begin{tabular}{c|}
$\begin{array}{c}\text { med. } \\
\text { infastruktur }\end{array}$ \\
7 \\
\end{tabular}} & \multirow{2}{*}{\begin{tabular}{c|}
$\begin{array}{l}\text { nicht med. } \\
\text { infastruktur }\end{array}$ \\
8 \\
\end{tabular}} & \\
\hline & & & & $4 a$ & $4 b$ & & $6 a$ & $6 b$ & & & \\
\hline 01. Normalstation & 485,9 & $1.510,2$ & 51,2 & 179,6 & 75,0 & 0,0 & 128,3 & 8,1 & 237,8 & \begin{tabular}{c|c|}
910,7 \\
\end{tabular} & $3.586,8$ \\
\hline 02. Intensivstation & 86,0 & 197,0 & 3,0 & 21,6 & 7,7 & 0,0 & 28,7 & 2,7 & 31,0 & 103,6 & 481,3 \\
\hline 04. OP-Bereich & 1,7 & 0,0 & 1,0 & 0,1 & 0,0 & 0,0 & 0,9 & 1,3 & 0,8 & 1,1 & 6,8 \\
\hline 05. Anästhesie & 3,0 & 0,0 & 2,1 & 0,2 & 0,0 & 0,0 & 0,6 & 0,1 & 0,5 & 0,9 & 7,4 \\
\hline 07. Kardiologische Diagnostk / Ther: & 0,7 & 0,0 & 1,1 & 0,0 & 0,0 & 0,0 & 0,4 & 1,0 & 0,7 & 0,8 & 4,7 \\
\hline 08. Endoskopische Diagnostk / Ther & 19,8 & 0,0 & 21,5 & 1,0 & 0,2 & 0,1 & 11,1 & 0,7 & 10,4 & 15,4 & 80,1 \\
\hline 09. Radiologie & 22,4 & 0,0 & 34,4 & 0,3 & 0,0 & 0,0 & 8,9 & 7,7 & 11,2 & 22,3 & 107,1 \\
\hline 10. Laboratorien & 15,5 & 0,0 & 97,3 & 3,1 & 13,7 & 0,0 & 70,3 & 65,3 & 9,9 & 42,9 & 317,9 \\
\hline 11. Übrige diagnosische und therape & 37,4 & 2,0 & 129,5 & 2,4 & 0,0 & 0,0 & 10,7 & 3,1 & 11,9 & 61,0 & 258,0 \\
\hline Summe: & 672,3 & $1.709,3$ & 341,1 & 208,1 & 96,7 & 0,1 & 259,8 & 89,9 & 314,1 & $1.158,6$ & $4.850,0$ \\
\hline
\end{tabular}

DRGs are common instruments for hospital reimbursement or budget allocation in most developed countries in the World. Nearly every country in Europe has DRG-systems in use [15].

Without drilling too deep into the complicated German DRG System and translating all the DRG-denominators, we point out, that DRG payments for one particular set of conditions - like respiratory tract infections - vary according to various cost-modifiers. One of these factors is the occurence of multiresistent bacteria (see bold letters in the table).

However, the payment for a given DRG is fixed at a certain amount. The German costing study includes annually calculated average costs in a matrix of cost types (such as staff, pharmaceuticals, etc.) and cost centers (such as normal ward, OR, ICU, etc.). This results in a costing matrix with up to 100 so-called cost modules. Moreover a national LOS "benchmark" is available, and these data are published in the internet (for each DRG). After the introduction of DRGs, optimizing the LOS has turned out as an important lever to achieve higher profitability [11]. Yet, this notion has not yet been fully acknowledged by everyone in the medical community [12].

As an example, Table 2 shows the cost matrix of E77B - Respiratory infections with complex diagnosis 
Table 3. Entity relationship model of the „decoding infections“ database.

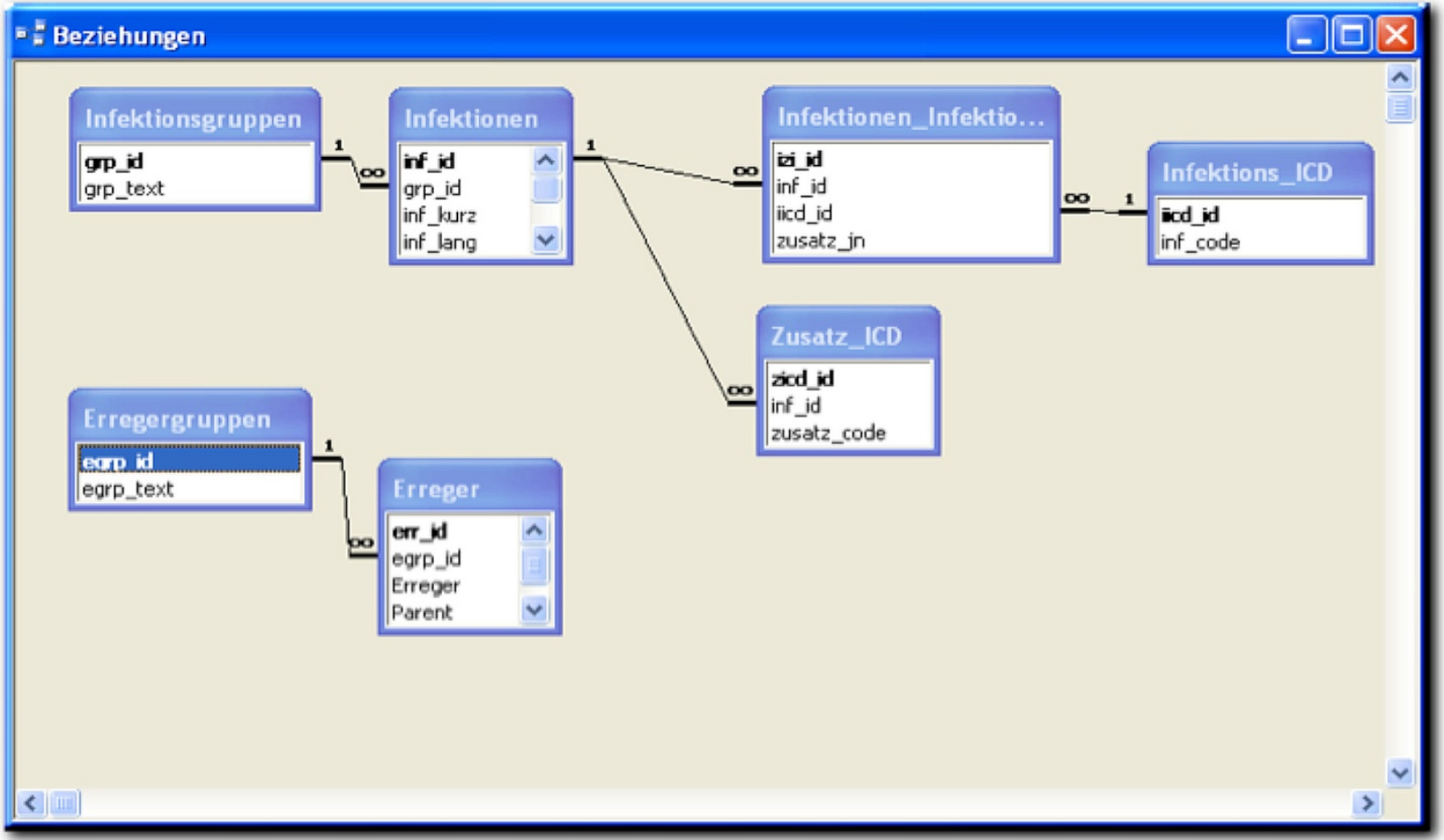

or catastrophic CC, w/ o complex intensive care for children, with treatment of multiresistent bacteria, hospital stay longer than 72 hrs

Based on the known „limits“ that must be observed to avoid losing money in DRG-reimbursed treatments, analyses can be done on an individual hospital's data to determine whether the current treatment strategies in a hospital lead to a sustainable balance of cost and medical need $[13,14]$.

Coming from this idea, the development of a DRG-based approach to the analysis of infections and the prove-of-concept were the major questions to be dealt with in this publication.

\section{Materials And Methods}

As in DRG-based payment systems, the coding of diagnoses as primary (the reason why the patient got admission to the hospital) and secondary (relevant complications and comorbidities that caused resource consumption) diagnoses is the cornerstone of finding the correct DRG, we assumed that the coding quality in terms of completeness and accuracy pretty well reflects the clinically relevant situation, especially in case of infections. We developed an algorithm that contains over 100 ICDcodes representing infections and/or bacterial pathogens. Hospital-acquired versus communityacquired infections were assumed to be represented by the assignment as „primary“ (or main) diagnosis or „secondary“ diagnosis. Moreover, we tried to rule out coding errors such as the implausible use of the same ICD code as primary and secondary diagnosis. Hospital acquired pneumonias (HAP) may be indicated by a special ICD-code (U69.00!) used to distinguish between community acquired pneumonia (CAP) and HAP in the German system.

Using the minimal basic dataset (MBDS) of a country - in Germany it is defined by $\$ 21$ of the hospital financing act and thus called \$21-data - for one hospital or a set of hospitals, it is possible to „decode“ infections from the DRG data.

Table 3 displays the basic data model used to retrieve information on infections and bacterial pathogens from coded ICD-10 data.

As in some cases, bacterial pathogens are part of the ICD-code of the infections, counting infections and the bacteria involved respect this fact by listing some ICD-codes as infections and as bacteria.

See Table 4 for an example.

Using this methodology, we were able to decode infections from routine DRG data. After implementation of these data in a business information warehouse (BI) software, it is now possible to answer the following questions:

- Which infections caused by which bacteria occur in the hospitals?

- Which LOS is associated to which infection and does it imply a risk of losing reimbursement for the hospital?

Which DRGs are the ones most likely impacted by infections?

Once identified, the DRGs with a high number of infections or those patients that cause the highest loss in DRG-reimbursement due to infections may be further analyzed.

In peer reviews, the antibiotic therapy strategy for each case may be compared against the expected cost average in the respective DRG, the actual cost and the 
Table 4. Association of bacterial pathogens and ICD-codes..

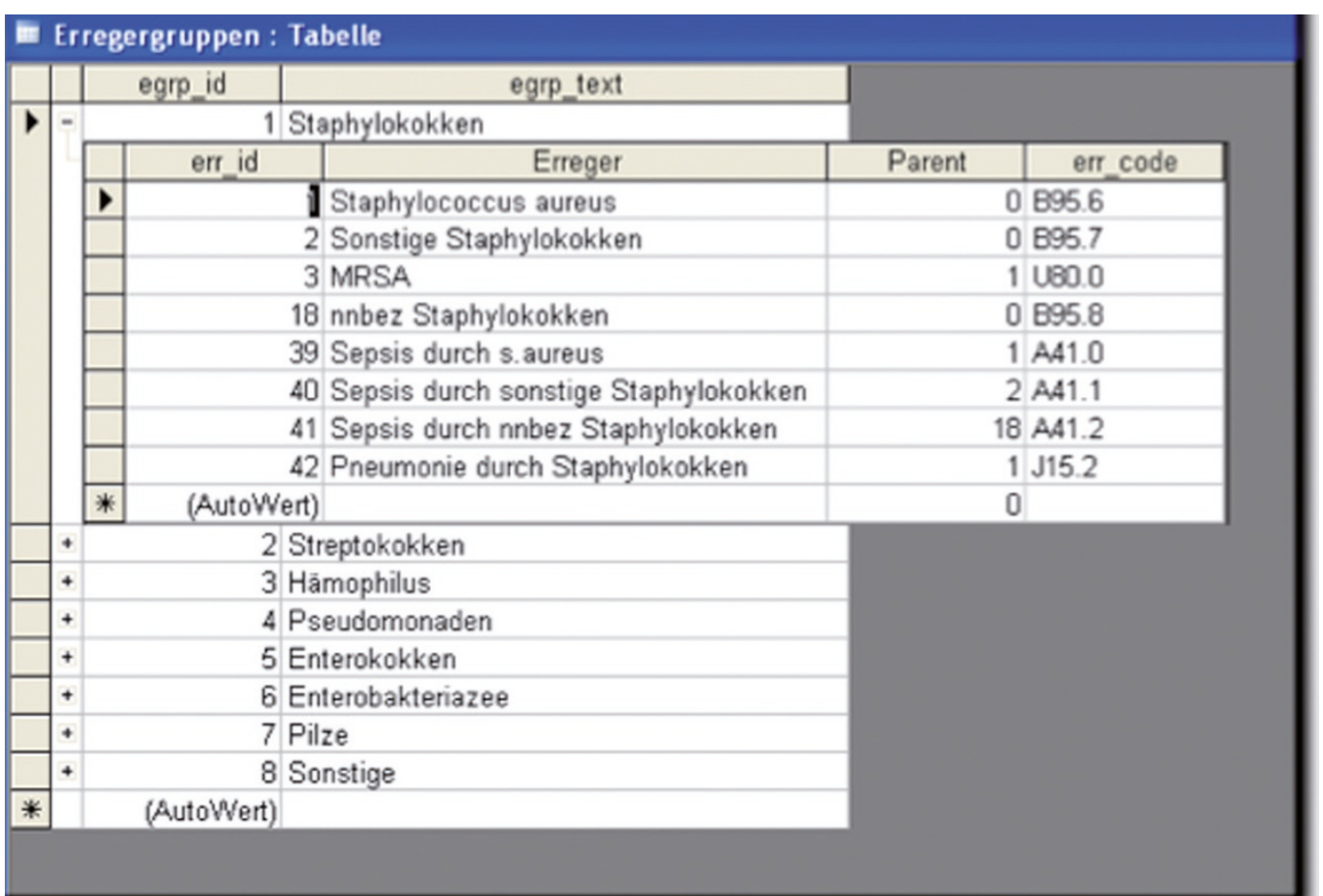

potential cost outcome achieved by using a different therapeutic strategy.

\section{RESULTS}

Differences in length of stay that cause inefficiency can be detected and assigned to various types of infections.

Table 5 shows an overview of certain infections and the LOS of patients having these infections compared to the LOS of patients being in the hospital without an infection.
If the LOS is higher with an infection, this does not necessarily imply that there is an economic loss for the hospital, as expensive cases usually also entail more revenue. By knowing that LOS is the key cost driver in a DRG-based system, an analysis can be performed how many patients meet the average LOS (ALOS) of the DRG - as defined by the national benchmark - and how many patients stay longer. Those patients staying longer are the patients that cost more than the hospital is reimbursed for.

Table 5. LOS with and without infections.

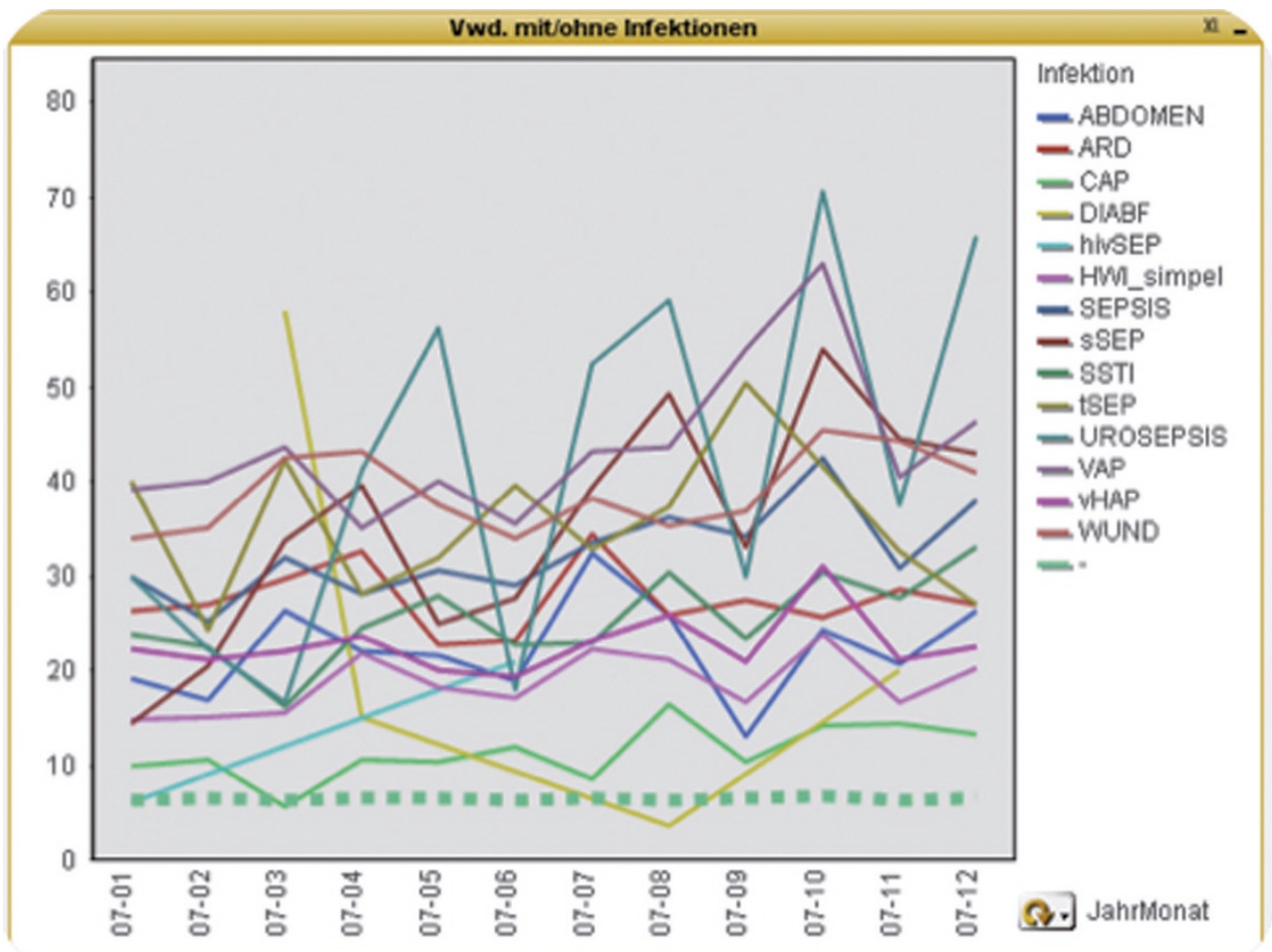

Without infections: 7,3 days (green block line)

With hospital acquired pneumonia (HAP) 21-28 days (pink line) 
Table 6. LOS for all patients of a hospital - good result: 76\% of all patients can be discharged before reaching the ALOS (mVD in the figure).

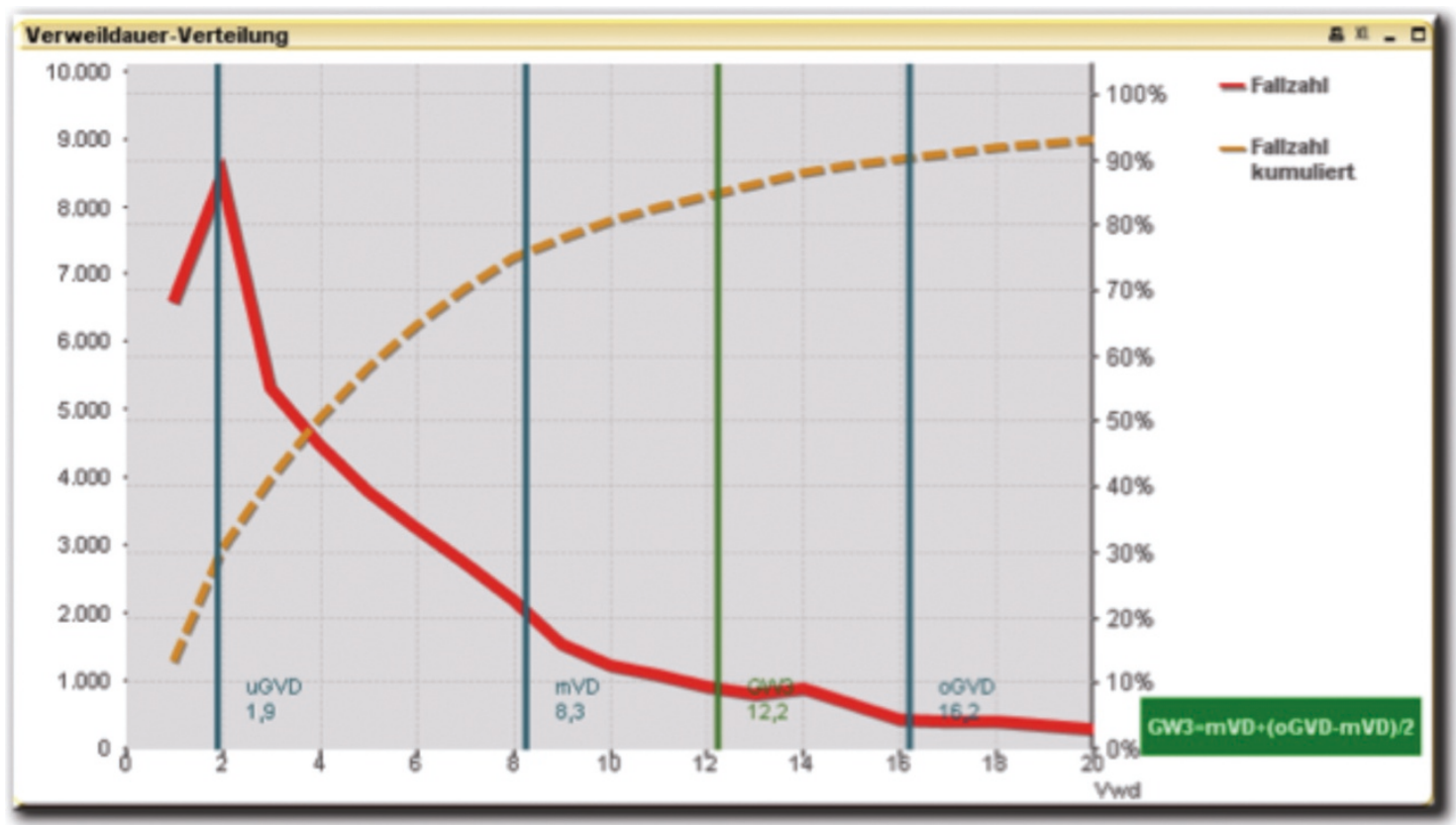

Table 7. LOS distribution for patients with postoperative infections. Although the national ALOS of these DRGs is 21.9 days (indicating that the DRG-reimbursement is higher than the hospital average) only $50 \%$ of these patients can be discharged before ALOS. That means half of the patients cost presumably more than the hospital is being reimbursed for.

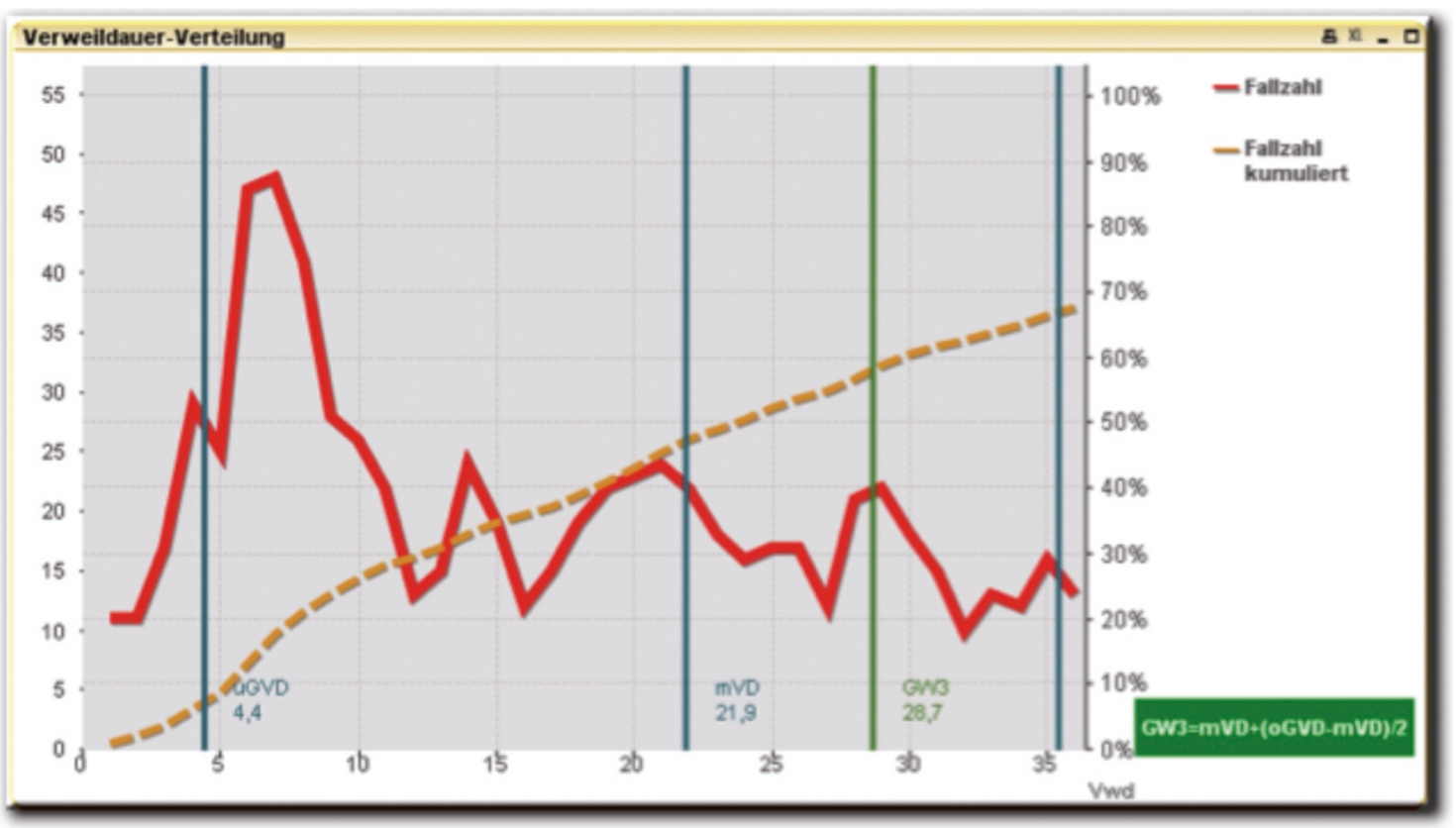

Tables 6 and 7 display LOS curves (absolute $=$ red curve, cumulative $=$ brown curve) for 1 ) all patients in a hospital and 2) patients having a postoperative infection such as wound infections, peritonitis or other OR-related infections:

Using individual patient cases for analysis, the individual DRG may be used and the actual antibiotic therapy strategy may be compared versus an optimum setting. Quite often it is possible to show that a stateof-the art therapy causes less cost.
Table 8 shows a case simulation for a given DRG result (A13E - mechanical ventilation 95-250 hrs). By examining the medical record, the reviewers found that by optimizing antibiotic therapy (i.e. starting the eventually effective therapy with tigecycline 3 days earlier) the ICU-stay and the LOS could have been 2 days shorter. Moreover, by starting the adequate therapy earlier, three days of ineffective and expensive therapy (in this case meropenem plus ciprofloxacin) could have been avoided. In the end, the hospital would have had small gain 
Table 8. DRG and individual case-based simulation of optimized antibiotic therapy strategies.

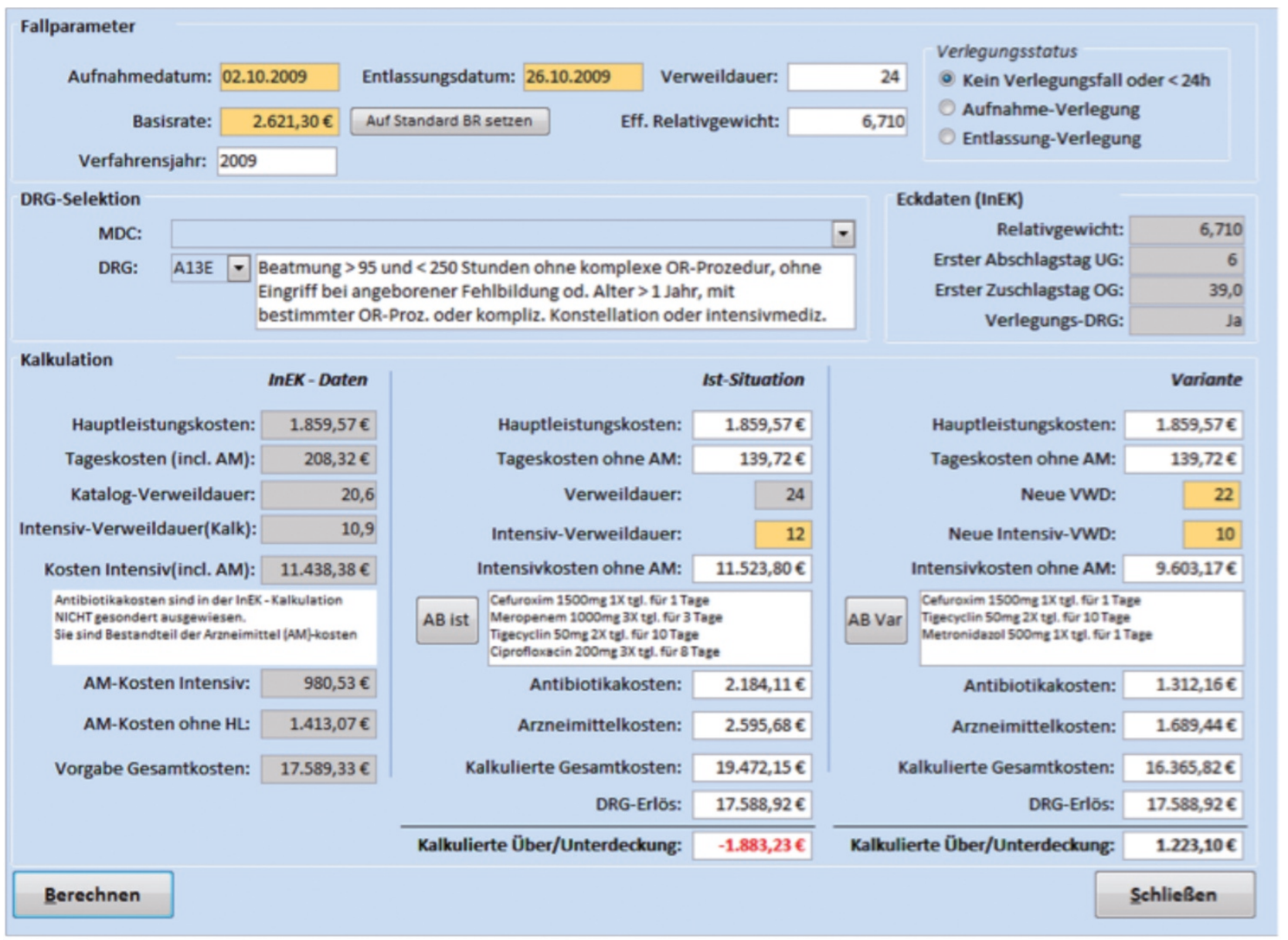

in this DRG rather than a loss as in the original situation. Comparing national standard cost (section "InEKDaten" in the picture) with actual cost (section "Ist-Situation") shows that the hospital spends more than it is reimbursed $(-1,881.23 €)$. By simulating the case with the optimized therapy option (section "Variante" in the picture) the economic result shows a surplus of 1,223.10€.

The findings of other studies and the results from the data easily can be reproduced also in the results of individual case reviews. The main cost drivers are:

- Length of stay in hospital $\rightarrow$ Possible reason: Delayed start of effective antibiotic therapy

- Complications related to antibiotic therapy $\rightarrow$ most frequent: renal failure

- Use of inadequate antibiotics that turn out to be ineffective

- Longer ICU stay

- Prolonged duration of mechanical ventilations

\section{Discussion}

Decoding infections from DRG routine data is feasible, comparatively easy and can be done with little effort of time and expenses as the data are easily available for each hospital. Validations in several hospitals were done by using the results and reviewing selected medical records to verify whether the „decoded“ infection was actually mentioned in the record. Very lit- tle variances were found to be due to coding variations. While Germany has coding standards for diagnoses and procedures, errors may still occur. The actual accuracy of the coding is very good. According to the medical services of the statuary health insurance in Germany (MDS) 11\% of all hospital DRG reimbursements are claimed to be wrong and in $40 \%$ of the claims actual errors are found. That means that nearly $96 \%$ of the coding is correct, as no claim is issued or no error is found [15].

It is clearly possible to identify cases that are more expensive than the DRG system recommends. In many of these cases, sound medical reasons caused the extended LOS, but there is a substantial part of the reviewed cases that suggest opportunities to optimize the antibiotic therapy strategy.

\section{CONCLUSIONS}

Analysis on the basis of DRG routine data is an easy way to "decode" infections in a hospital setting and directly connect them to economic results.

Establishing a peer review of the medical records of cases producing financial loss may identify opportunities to optimize treatment strategies.

LOS, number of complications, ICU-days and hours of mechanical ventilation are good endpoints to be used in the assessment of the economical effects of individual antibiotics. 


\section{REFERENCES}

1. J. Boldt, Können wir uns die Fortschritte der Intensivmedizin noch leisten? Deutsche Medizinische Wochenschrift 2004; 129 (1/2): 36-40

2. Rubio-Terrés C; Garau J; Grau S; Martinez-Martinez L, Cost of bacteraemia caused by methicillin-resistant vs. methicillin-susceptible Staphylococcus aureus in Spain: a retrospective cohort study., Clinical microbiology and infection : the official publication of the European Society of Clinical Microbiology and Infectious Diseases; VOL: 16 (6); p. 722-8 /201006/

3. Lee SY, Kotapati S, Kuti JL, Nightingale CH, Nicolau DP, Impact of extended-spectrum beta-lactamase-producing Escherichia coli and Klebsiella species on clinical outcomes and hospital costs: a matched cohort study, Infect Control Hosp Epidemiol. 2006 Nov;27(11):1226-32.

4. Wernitz MH, Lenz C, Veit SK. Die Bedeutung von Infektionen durch multiresistente Staphylococcus aureus für das deutsche Gesundheitswesen - The (n)ever ending story? J Pharmakol Ther 2009:18;75-82.

5. Fowler $\mathrm{V}$ et.al, Daptomycin versus standard therapy for bacteremia and endocarditis caused by Staphylococcus aureus, N Engl J Med. 2006 Aug 17;355(7):653-65.

6. Resch A, Wilke M, Fink C, The cost of resistance : Incremental cost of methicillin-resistant Staphylococcus aureus (MRSA) in German hospitals. Eur J Health Econ. 2009 Jul;10(3):287-97.

7. Sculpher MJ, Pang FS, Manca A, Drummond MF, Golder S, Urdahl H, Davies LM, Eastwood A.; Generalisability in economic evaluation studies in healthcare: a review and case studies; Health Technol Assess. 2004 Dec;8(49):iii-iv, 1-192.

8. Facey K, Boivin A, Gracia J, Hansen HP, Lo Scalzo A, Mossman J, Single A; Patients' perspectives in health technology assessment: a route to robust evidence and fair deliberation; Int J Technol Assess Health Care. 2010 Jul;26(3):334-40.

9. Greenberg D, Rosen AB, Wacht O, Palmer J, Neumann PJ; A bibliometric review of cost-effectiveness analyses in the economic and medical literature: 1976-2006; Med Decis Making. 2010 May-Jun;30(3):320-7. Epub 2010 Mar 12.
10. Harris AH, Hill SR, Chin G, Li JJ, Walkom E; The role of value for money in public insurance coverage decisions for drugs in Australia: a retrospective analysis 1994-2004; Med Decis Making. 2008 Sep-Oct;28(5):713-22. Epub 2008 Mar 31.

11. Heller AR, Bauer KR, Eberlein-Gonska M, Albrecht DM, Koch T; Regional anaesthesia as advantage in competition between hospitals. Strategic market analysis; Anaesthesist. 2009 May;58(5):459-68.

12. von Weizsäcker F, Maio G; Ethical insolvency?; Dtsch Med Wochenschr. 2010 Apr;135(16):819-21.

13. InEK GmbH; G-DRG System 2010; available online on: http://www.g-drg.de/cms/index.php/G-DRG-System_2010/Fallpauschalen-Katalog/Fallpauschalen-Katalog_2010

14. InEK GmbH; G-DRG Report-Browser 2008/2010; available online on: http://www.g-drg.de/cms/index.php/G-DRGSystem_2010/Abschlussbericht_zur_Weiterentwicklung_ des_G-DRG-Systems_und_Report_Browser / Report-Browser_2008_2010

15. Pick P, Busley A; MDK - Prüfungen im Krankenhaus, Oral presentation, Dt. Krankenhaustag 2009, Nov 19th 2009

www.deutscher-krankenhaustag.de/de/.../pdf/09_Pick.pdf

16. Leister JE, Stausberg J, Comparison of cost accounting methods from different DRG systems and their effect on health care quality, Health Policy. 2005 Sep 28;74(1):4655

Received: October 24, 2010 / Accepted: November 12, 2010

Address for correspondence:

Dr. Wilke $\mathrm{GmbH}$ - inspiring.health Joseph-Wild-Str. 13

81829 München

Germany

Tel.: $\quad+49(8) 89-18908376-0$

Fax: +49(8)89-18908376-9

E-mail: michael.wilke@d-w-g.de 